\title{
COMPORTAMENTO DO FOGO, EM CONDIÇÕES DE LABORATÓRIO, EM COMBUSTÍVEIS PROVENIENTES DE UM POVOAMENTO DE Pinus elliottii L.
}

\author{
Luciana Valle de Loro $^{1}$ \\ Nelson Akira Hiramatsu ${ }^{2}$
}

\begin{abstract}
RESUMO
De um povoamento de Pinus elliottii localizado na Fazenda Canguiri-UFPR, foram coletadas seis amostras de material combustível superficial. Este material foi separado em classes, pesado e levado para o laboratório. Efetuou-se a queima da classe acículas num leito de areia no laboratorio, em seis queimas, sendo cada queima com acículas proveniente de cada uma das amostras coletadas. Foram medidas a altura, o comprimento e a velocidade de propagação do fogo. Aplicou-se para cada queima cerca de $746 \mathrm{~g}$ de acículas, equivalente a 0,678 $\mathrm{Kg} / \mathrm{m}^{2}$, com uma espessura média de $3 \mathrm{~cm}$. Foram obtidos como dados médios: velocidade de propagação de $0,00423 \mathrm{~m} / \mathrm{s}$, comprimento da chama de $35,22 \mathrm{~cm}$ e altura de $38,79 \mathrm{~cm}$, resultando numa intensidade do fogo igual a $57,07 \mathrm{~kW} / \mathrm{m}$. O resíduo médio ficou na ordem de $40,3 \%$.

Palavras-chave: carga, material combustível, resíduo de combustível, queima controlada, temperatura da chama
\end{abstract}

FIRE BEHAVIOR, IN LABORATORY CONDITIONS, OF FOREST FUELS FROM A Pinus elliottii L. STAND

\begin{abstract}
Pinus elliottii needles from a stand located at Fazenda Canguiri-UFPR were collected to run a laboratory test on fire behavior. The fuel from six samples was separated in classes, weight, and taken to the Federal University of Paraná Forest Fire Laboratory. The pine needles were burned in a sand bed. About $746.0 \mathrm{~g}$ of each one of the six samples, equivalent to $0.678 \mathrm{~kg} . \mathrm{m}^{-2}$ and $3 \mathrm{~cm}$ depth, were used in each fire run. Flame height and length, and rate of spread were measured. The average values obtained were: fire spread, $0,00423 \mathrm{~m} \cdot \mathrm{s}^{-1}$, flame length, $35,22 \mathrm{~cm}$, and flame height, $38,79 \mathrm{~cm}$. Fire intensity was of $57,07 \mathrm{~kW} \cdot \mathrm{m}^{-1}$ and residual fuel content about $40,3 \%$.

Keyword: Forest fuel, residue of fuel, controlled burn, fire behavior.
\end{abstract}

\section{INTRODUÇÃO}

As florestas tanto naturais como plantadas proporcionam um significativo beneficio social, ambiental e econômico para uma região. Todos esses benefícios dependem do bom planejamento de implementação florestal, o que inclui fases desde estudos para a seleção da área a ser trabalhada e suas características, até um cronograma definido de atividades específicas.

Deve-se relevar a existência de uma relação entre o fogo e a silvicultura durante a implantação e o manejo de uma floresta. A combustão é entendida como processo de decomposição, sendo o inverso da fotossíntese. Esta última resulta da combinação de água, dióxido de carbono e energia solar que produzem celulose e outros carboidratos. A combustão que é o processo inverso libera, sob forma de calor, a energia armazenada pela fotossíntese.

O processo de combustão, sendo uma reação de oxidação, ocorre pela combinação entre o oxigênio e uma substância combustível, induzida por uma fonte externa de calor (Batista, 1990). Na ausência de qualquer um desses fatores não há possibilidade de ocorrência de ignição.

O oxigênio compõe aproximadamente $21 \%$ do ar atmosférico, tendo estudos demonstrado que se reduzido a $15 \%$ ou menos, torna inviável a combustão.

A fonte de calor suficiente para elevar a temperatura de um material à temperatura de ignição varia de acordo com o material combustível, sendo que para os combustíveis

\footnotetext{
florestalu@yahoo.com.br, graduando de Eng. Florestal, UFPR, Rua Benjamin Constant, 229 apto 502, Curitiba - PR

2 nelsonakira@hotmail.com, graduando de Eng. Florestal, UFPR, Rua Pres. Carlos Cavalcanti, 239 apto 111, Curitiba - PR
} 
florestais está entre 260 e $400{ }^{\circ} \mathrm{C}$.

O combustível, em uma floresta, pode ser classificado como toda a matéria orgânica que se encontra depositada na superfície do local.

A ocorrência de incêndios florestais constitui-se em uma preocupação que mobiliza uma grande soma de esforços e recursos nas operações de combate. A previsão do nível de perigo de um incêndio constitui um elemento fundamental para a proteção das florestas contra esta ameaça, permitindo uma melhor gestão dos meios de combate. Esses incêndios provocam prejuízos ao homem e ao ambiente, tendo também conseqüências econômicas consideráveis.

Tendo esses conceitos, o presente trabalho objetivou analisar algumas características do comportamento do fogo a partir de combustíveis florestais depositados no povoamento de $P$. elliottii da área em questão.

\section{MATERIAIS E MÉTODOS}

A coleta do material combustível foi realizada no dia 05 de dezembro de 2003, na fazenda do Canguiri, pertencente a Universidade Federal do Paraná. O material combustível foi coletado dentro de uma área delimitada de $20 \times 20 \mathrm{~m}$ sob um povoamento de Pinus elliottii com 21 anos de idade, com uma densidade de 1150 arv/ha. Foram medidos os CAP's, obtendo-se uma média de 71,34 cm, correspondendo a um DAP médio de $22,7 \mathrm{~cm}$.

Desta área foram coletadas seis parcelas de $1 \times 1 \mathrm{~m}$ de material combustível. Cada parcela teve as espessuras da manta nas quatro laterais medidas. O material de cada parcela foi dividido em classes, sendo as classes: acículas, material vivo (verde), material com diâmetro menor que $0,7 \mathrm{~cm}$, material com diâmetro entre 0,7 e $2,5 \mathrm{~cm}$ e material com diâmetro entre 2,5 e 7,6 cm. Em seguida, fez-se a pesagem em campo de cada classe de combustível coletado. Foram medidas ainda a declividade do local em quatro pontos através de um clinômetro, determinada a posição da área coletada através de um GPS em três pontos distintos da área de $20 \times 20 \mathrm{~m}$ e a temperatura do bulbo seco e úmido através de um psicrômetro portátil, com seis medições em intervalos de 15 minutos.
A área delimitada apresentou declividade média de $4,2 \%$, estando localizada na posição $25^{\circ} 23^{\prime}$ latitude sul e de $49^{\circ} 07^{\prime}$ longitude oeste.

Do material combustível obtido nas parcelas foram retiradas sub-amostras que foram devidamente pesadas e transportadas ao laboratório de incêndios florestais do curso de Engenharia Florestal da UFPR. No laboratório as sub-amostras foram secas em estufa $\left(75^{\circ} \mathrm{C}\right.$ por 48 horas). Pesou-se então o material já seco para, por diferença, determinar o teor de umidade do material.

No momento da coleta a temperatura ambiente marcou uma média de $21^{\circ} \mathrm{C}$ e a umidade relativa era de $85 \%$ (variando de 90 a $77 \%)$.

Do material seco amostrado, utilizouse a classe das acículas para se efetuar a queima controlada em laboratório. A queima foi efetuada sobre um leito horizontal de areia com uma área de 1,102 m2 (dimensões de 145 x $75 \mathrm{~cm}$ ), onde se mediu a velocidade de propagação do fogo, a altura e o comprimento da chama. As medidas eram tomadas a partir de treze pontos de observação, em intervalos de distâncias iguais de $10 \mathrm{~cm}$, em toda a extensão do leito. No início e no final de cada queima se coletava a temperatura e umidade relativa do laboratório de um termômetro/psicrômetro de parede do laboratório. Durante o experimento, no laboratório, a temperatura média foi de $24{ }^{\circ} \mathrm{C}$ e a umidade média de $68,5 \%$.

Foram feitas ao todo seis queimas das acículas, sendo que cada uma era proveniente de cada amostra coletada no campo. A carga média utilizada para as queimas foi de 0,678 $\mathrm{Kg} / \mathrm{m}^{2}$, utilizando-se de cerca de $746 \mathrm{~g}$ de acículas para cada queima e uma espessura média de $3 \mathrm{~cm}$ de espessura no leito. Para todas as queimasd foram estimados os valores de razão de compactação (média de 0,0458, variando de 0,0364 a 0,0661$)$ e umidade de extinção (média de $34 \%$, variando de 29,471 a $43,765 \%$ ). A razão de compactação é um valor que varia de 0 a 1 e está diretamente relacionada com a densidade do material, quanto mais próximo de 1 maior é a compactação. A umidade de extinção indica a umidade acima da qual não há possibilidade de combustão. 
Foi feita ainda uma amostragem do resíduo, sendo coletado e pesado após cada queima o combustível não consumido, de uma de área de $30 \times 30 \mathrm{~cm}$ do leito. O material não queimado era pesado e comparado com o peso do material original (antes da queima) na mesma área de $30 \times 30 \mathrm{~cm}$. Os dados eram extrapolados para toda a área do leito, determinando-se a porcentagem de resíduo (e conseqüentemente de material queimado) restante após cada queima.

\section{RESULTADOS, DISCUSSÕES E CONCLUSÕES}

$\mathrm{Na}$ tabela 1 estão apresentados os valores referentes à quantidade de material combustível (peso seco em estufa) por classe. Pode se observar que a classe de acículas representou cerca de $84 \%$ do peso total médio do material combustível analisado. Esta predominância da classe de acículas também foi verificada por outros autores, ao caracterizarem os combustíveis superficiais de plantios de Pinus. Batista (1995) verificou que em povoamentos de $P$. taeda, a classe de acículas representou $78,5 \%$ do peso total do combustível. Sacket (1980), Kaufmann e Martin (1989) também observaram resultados similares: a classe de acículas representou 65 a $84 \%$ do peso total do material combustível.

Outra característica importante do material combustível, associada à inflamabilidade do combustível é a espessura da manta, formada pela deposição gradual dos resíduos orgânicos. A espessura média da manta foi de $4,4 \mathrm{~cm}$.

Tabela 1: Peso do material combustível superficial seco em estufa (em g/m² $)$, sob o povoamento de P. elliottii

\begin{tabular}{cccccc}
\hline Parcelas & Acículas & Vivo & $\begin{array}{c}<\text { Classes } \\
\mathbf{0 , 7}\end{array}$ & $\mathbf{0 , 7} \mathbf{- 2 , 5}$ & $\mathbf{2 , 5 1 - 7 , 6}$ \\
\hline $\mathbf{1}$ & 1358,7 & 0,0 & 79,9 & 295,8 & 124,2 \\
$\mathbf{2}$ & 1362,8 & 2,8 & 0,0 & 0,0 & 9,1 \\
$\mathbf{3}$ & 2434,9 & 0,0 & 64,8 & 172,0 & 246,5 \\
$\mathbf{4}$ & 986,1 & 0,0 & 0,0 & 50,3 & 122,8 \\
$\mathbf{5}$ & 1466,7 & 15,0 & 0,0 & 0,0 & 0,0 \\
$\mathbf{6}$ & 1567,1 & 0,0 & 43,2 & 243,3 & 95,5 \\
\hline Média & 1529,4 & 2,9 & 55,4 & 126,9 & 99,7 \\
\hline
\end{tabular}

Os valores observados para as variáveis do comportamento do fogo estão apresentados na tabela 2. Estes resultados referem-se à média de 13 observações, em cada queima.

A velocidade média obtida $(0,423$ $\mathrm{cm} / \mathrm{s}$ ), foi superior a obtida por Gillon et all (1995) que fez um experimento de queima de acículas de Pinus pinaster em laboratório e encontrou uma velocidade média de propagação de $0,26 \mathrm{~cm} / \mathrm{s}$. Contudo naquele experimento a espessura da manta utilizada nas queimas foi de $3,65 \mathrm{~cm}$ e a razão de compactação de 0,04 , enquanto neste experimento utilizou-se uma espessura média de acículas de 3,0 cm, mantendo-se a razão de compactação próxima de 0,04 .

Utilizando-se como calor de combustão o valor de $19.900 \mathrm{~kJ} / \mathrm{Kg}$, obteve-se uma intensidade média do fogo de 57,07
$\mathrm{kW} / \mathrm{m}$ (através da fórmula de Byram: $\mathrm{I}=\mathrm{W} \mathrm{x}$ $\mathrm{H} \times \mathrm{r}$ ). A intensidade do fogo obtida por Gillon et al (1995) variou de 40 a $56 \mathrm{~kW} / \mathrm{m}$, ficando pouco abaixo do valor médio obtido nesse experimento.

O comprimento de chama médio obtido foi de $35,22 \mathrm{~cm}$ e a altura média das chamas foi de $38,79 \mathrm{~cm}$. Esse resultado, a altura maior que o comprimento, é contraditório, pois na realidade a altura pode chegar a ser no máximo igual ao comprimento da chama. De forma geral, isso ocorreu em quase todos as observações destas duas variáveis. Essa contradição só foi notada somente na análise dos dados e a provável causa disso é um erro no modo de medição dessas duas variáveis, que sempre foi feita por duas pessoas distintas, sendo uma medindo o comprimento e outra a altura da chama. 
Tabela 2: Velocidade de propagação, comprimento e altura da chama em queimas experimentais de cama de acículas

\begin{tabular}{cccc}
\hline Queimas & $\begin{array}{c}\text { Veloc. de propagação } \\
(\mathrm{cm} / \mathrm{s})\end{array}$ & $\begin{array}{c}\text { Comprimento } \\
(\mathrm{cm})\end{array}$ & $\begin{array}{c}\text { Altura } \\
(\mathrm{cm})\end{array}$ \\
\hline $\mathbf{1}$ & 0,383 & 32,62 & 39,96 \\
$\mathbf{2}$ & 0,481 & 39,77 & 41,23 \\
$\mathbf{3}$ & 0,426 & 27,31 & 46,62 \\
$\mathbf{4}$ & 0,433 & 49,54 & 51,73 \\
$\mathbf{5}$ & 0,346 & 31,77 & 27,31 \\
$\mathbf{6}$ & 0,471 & 30,31 & 25,92 \\
\hline Média & 0,423 & 35,22 & 38,79 \\
\hline
\end{tabular}

$\mathrm{Na}$ amostragem do resíduo obteve-se uma média de $336,7 \mathrm{~g}$. Isto corresponde a uma média $40,3 \%$ de resíduos, conseqüentemente $59,7 \%$ das acículas foi queimado. Considerando que nas condições controladas do laboratório e com o material seco a porcentagem de resíduos foi de $40,3 \%$, podese dizer que em condições semelhantes no campo teríamos uma porcentagem de resíduos muito maior, pois o material de campo se encontraria mais úmido. Contudo, outras variáveis como a presença de vento e a declividade local, influenciariam grandemente nas condições de queima. O combustível consumido, 59,7 \%, foi baixo quando comparando com o experimento de Gillon et al (1995), que obteve consumo de combustivel superior a $80 \%$.

Os resultados obtidos permitem concluir que o estudo do comportamento do fogo em queimas de acículas de Pinus elliotii, através de simulação em condições controladas de laboratório, é viável, sendo que os resultados obtidos foram similares aos resultados de experimentos realizados por outros autores. Pelos resultados obtidos também pode se concluir que é possível avaliar o comportamento do fogo, em condições de laboratório, desde que sejam descritas adequadamente as características do material combustível e controladas as condições do laboratório.

\section{REFERÊNCIAS}

BATISTA, A.C. Avaliação de queima controlada em povoamentos de Pinus taeda no norte do Paraná. Curso de Pós-Graduação em Engenharia Florestal, Curitiba. 1995, p. 5051. (Tese de doutorado).

BATISTA, A.C. Incêndios Florestais. Recife, Universidade Federal Rural de Pernambuco, 1990. p.5.

CIANCIULLI, P.L. Incêndios Florestais Prevenção e controle. São Paulo, Nobel, 1981. p. 51-61.

GILLON, D. et all. Combustion and Nutrient Losses During Laboratory Burns. The International Journal_of Wildland Fire, v. 5, n. 1, p. 1-12. 1995.

KAUFFMANN, J. B.; MARTIN, R. E. Fire behavior, fuel consumption, and forest-floor changes following prescribed understory fires in Sierra Nevada mixed conifer forests. Can. J. For. Res., Otawa, v. 19, p. 455-462, 1989.

SACKETT, S. S. Scheduling precribed burns for hazard reduction in southeast. Journal of Forestry, Washington, v. 73, n. 3, p. 143-147, 1975.

SOARES, R.V. Prevenção e controle de Incêndios Florestais. Curitiba, FUPEF, 1979. p. 1-20. 